\title{
Serial learning without primacy or recency effects'
}

\section{E. RAE HARCUM AND EDWIN W. COPPAGE}

THE COLLEGE OF WILLIAM AND MARY

\begin{abstract}
Data from learning by the anticipation method 10 homogeneous nonsense syllables, presented without an intertrial gap, show that temporal primacy and recency per se are not involved in the production of the classical serial-position curve of rote learning. Only negligible differences among item-positions appeared early in learning, when differential effects of proactive inhibition among the individual items should have been maximal, but a primacy effect did appear later. This primacy effect was attributed to S's strategy in selecting a syllable, differentiated on the basis of being temporally first, as a reference point around which the complete list was finally learned.

\section{Problem}

Temporal primacy and recency effects in serial learning have been demonstrated repeatedly, even when the usual temporal gap between successive trials is omitted (Glanzer \& Peters, 1962; Lippman \& Denny, 1964; Mitchell, 1933). The purpose of the present report is to show that the so-called primacy effect in serial learning is not produced by the relative absence of proactive inhibition for the first items of a list; it is related to another mechanism entirely. The actual mechanism involves S's strategy in selecting the order in which he will learn the items.

As Harcum \& Coppage (1965) suggest, in serial learning the $\mathrm{S}$ selects some item to belearned first, and then systematically adds other items to this anchor. With ordinary conditions of presentation the beginning and last syllables provide an excellent basis for localizing or anchoring individual items within the series.Glanzer \& Peters (1962) found that in fact the most important factor determining the asymmetrical serial-position curve was the gap between trials. However, the mere fact of beginning with a certain syllable can serve to mark that syllable as the beginning, since the serialposition effect is still obtained when there is no temporal gap between trials. Such data support a theory based on mnemonic organizational factors, rather than on differential effects of proactive and retroactive inhibition; Asch, Hay, \& Diamond (1960) concluded that S's cognition of a beginning and end of the series is critical to the serial-position effect.

Jenkins \& Dallenbach (1927) attributed the appearance of greater recency effects with free recall to the focusing of Ss' attention to the final item. 'Trimacy was explained in terms of an "initial set" toward the first syllable, causing it to be accented. This interpretation is supported by the results of Krueger (1932), who directed the attention of his Ss to the center of a list and found it easiest to learn. Therefore, the asymmetry of the distribu- tion of errors appears to be determined by the direction of S's attention toward one end of the series.

The present daia are the results of a subsequent further analysis of control data collected as part of a study on the relative effects of temporal primacy and structural isolation in continuous serial learning. ${ }^{2}$ Analysis of the experimental data indicated that Ss did not show strong effects of either temporal or structural primacy early in learning. This result fitted well with our earlier theorizing with respect to serial learning by the conventional technique (Harcum \& Coppage, 1965), but the lack of primacy effects could merely have been mutual cancellation of temporal- and structural-primacy tendencies. We decided to perform a similar analysis on our control data, which had been obtained with homogeneous nonsense syllables in continuous presentation and with minimal instructional stimulus. Our prediction was that there would be no effect of temporal primacy in the early stage of learning, but the effect would appear later as $\mathrm{S}$ began to use the temporally-differentiated first item as an anchor for the learning.

\section{Procedure}

A homogeneous list of $10 \mathrm{CVC}$ trigrams in a Gerbrands memory drum was presented continuously at a 3-sec. rate. Ss learned by the anticipation method to a criterion of 20 successive items correct, regardless of the syllable learned first. Five groups of four Ss each began on alternate syllables. Instructions to $\mathrm{S}$ were kept at a minimum, to avoid structuring the list. For example, no mention was made of first or beginning items.

\section{Results}

Figure 1 presents for each item-position the percentage of total errors during first and fourth quarters of learning, defined by totals of errors. If the primacy ef-

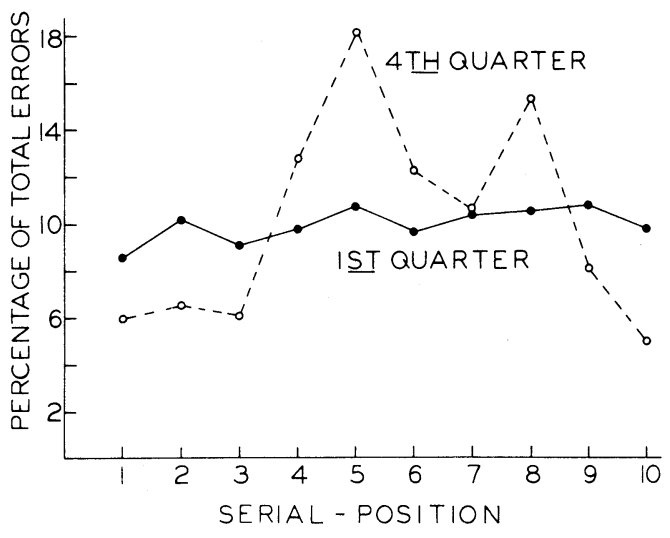

Fig. 1. Percentages at each syllable position of total errors in the first and fourth quarters of learning. 
fect is related to minimal effects of proactive inhibition, the curve for the first quarter of learning should show a minimum of errors about the temporally first item, with increasing numbers of errors for later items. The inhibitory effects must pile up at every item-position throughout successive trials, decreasing differential effects among items. However, there is virtually no effect of temporal primacy when its effect should be maximal if it is related to proactive inhibition.

Primacy and recency effects favoring the temporally first and last items, respectively, do appear later in the learning. These effects cannot be attributed to temporal primacy or recency per se since each item has been treated equally with respect to proactive and retroactive inhibitory effects since the first quarter of learning, during which no differential effects were found. Therefore, the primacy effect must develop later during the learning process.

\section{Diserussion}

Harcum \& Coppage's (1965) theory of serial learning accounts for the delay of a primacy effect under these conditions. They propose that the serial-learning process for a difficult task actually involves two components -anchor learning and serial learning proper. The first stige of the pr cess is learning the anchor. $\mathrm{S}$ ivegins the experiment with a set to learn first the item which he perceives as the first one in the list, unless special conditions (such as free recall) are employed. Thus, he first establishes one or several adjacent items at the perceived beginning of the series as an anchor to which other items are to be added. The second stage of the learning process-the actual serial learning-begins as items are added to this anchor, faster in the forward direction than in the backward direction. Evidence for this two-stage process is derived from errors per item-position for items ranked in the order of learning by individual Ss. Harcum \& Coppage (1965) found that unpracticed Ss learning 10-item lists of nonsense syllables had greater relative difficulty in acquiring the first-learned anchor-items than in the addition of the remainder of the items. The differential rates of forward and backward associations in the serial-learning stage account for the final asymmetrical distribution of errors.

Under ordinary conditions when the temporally first item is also the first item after the intertrial space, $\mathrm{S}$ perceives it quickly as the first item of the list, and primacy effects appear immediately (Robinson \& Brown, 1926). When the intertrial gap is omitted, $S$ must use some weaker basis, such as sheer temporal primacy, for structuring the list. Thus, in the present data for the first quarter of learning the results show the liststructuring process-the search for an anchor point. Therefore, there are negligible primacy effects. The final quarter of learning shows the results of serial learning-the progressive addition of items to an established anchor. The temporal primacy of one syllable, in the absence of any stronger basis of differentiation, became the basis for selecting the anchor; temporal primacy was effective only because it resulted in cognitive primacy.

The present interpretation supports Lippman \& Denny's (1964) argument that the primacy effect is caused by S's selection of the first syllable as an anchor for the learning, but it denies their contention that an intertrial gap is necessary for the serial-position effect. The present data casts doubt upon Lippman and Denny's apparent success in eliminating a primacy effect in serial learning, using continuous presentation and extralist items before the first syllable. Since learning was continued for 24 trials, rather than to some criterion of learning, the Es may merely have terminated the experiment before the primacy had a chance to develop an effect.

\section{References}

Asch, S. E., Hay, J., \& Diamond, R. M. Perceptual organization in serial rote learning. Amer. J. Psychol., 1960, 73, 177-198. Glanzer, M., \& Peters, S. C. Re-examination of the serial position effect. J. exp. Psychol., 1962, 64, 258-266.

Harcum, E. R., \& Coppage, E. W. Serial-position effect after prolonged practice. Psychol. Rep., 1965, in press.

Jenkins, J. G., \& Dallenbach, K. M. The effect of serial position upon recall. Amer. J. Psychol., 1927, 38, 285-291.

Krueger, W. C. F. Learning during directed attention. J. exp. Psychol., 1932, 15, 517-527.

Lippman, L. G., \& Denny, M. R. Serial position effect as a function of intertrial interval. J. verbal Learn. verbal Behav., 1964, 3, 496-501.

Mitchell, M. B. The effect of serial position in the continuous memorization of numbers. Amer. J. Psychol., 1933, 45, 493-494.

Robinson, E. S., \& Brown, M. A. Effect of serial position upon memorization. Amer. J. Psychol., 1926, 37, 538-552.

\section{Notes}

1. This investigation was supported by a PHS research grant (HD 00207-06) from the Institute of Child Welfare and Human Development, Public Health Service.

2. Submitted for publication. 